\title{
Virulence Factors and Molecular cloning of Outer Membrane Protein (OMP) gene from virulent Aeromonas hyrophila isolated from infected gold fish Carassius auratus
}

\author{
V Thanga Viji ${ }^{1}$, M Michael Babu ${ }^{1}$, S Velmurugan ${ }^{1,}$ T Kumaran $^{1}$, S B Anand ${ }^{2}$, \\ $\mathrm{P}_{\text {Gunasekaran }}{ }^{2}$ and T Citarasu ${ }^{1 *}$ \\ ${ }^{1}$ Centre for Marine Science and Technology, Manonmaniam Sundaranar University Rajakkamangalam, Kanyakumari District, Tamilnadu, India \\ 629502, ${ }^{2}$ NRCBS, School of Biological Sciences, Madurai Kamaraj University, Madurai, Tamilnadu, India 625021
}

(Received 08 September 2011; Accepted 03 December 2011)

\begin{abstract}
Aeromonas hyrophila strains AHV1, AHV2 and AH3 were isolated and identified from Muscle tissue, intestine, body fluid and gills of infected gold fish Carassius auratus. In order to study their virulence, $\mathbf{L D}_{\mathbf{5 0}}$ tests against normal gold fish, proteolytic, haemolytic and challenge studies were performed. The virulence studies revealed that, both AHV1 and AHV2 strains are highly positive for proteolytic and haemolytic properties. The $\mathrm{LD}_{50}$ data showed that, the fish $C$. auratus are highly susceptible to A. hyrophila strains AHV1 and AHV2 at cent percent lethal rate. The survival of $C$. auratus significantly $(\mathrm{P}<0.05)$ decreased when challenged with virulent strains of A. hydrophila AHV1 and AHV2. The outer membrane protein (OMP-TS) gene was successfully amplified generating an the amplicon size of $1008 \mathrm{bp}$. The amplified product from the genomic DNA of AHV1 strain was cloned in to $\mathrm{pTZ57R/T}$ vector, transformed into $\mathrm{DH}_{5} \alpha$ cells and sequenced. The sequenced clone is resembling to various $A$. hydrophila isolates and submitted to NCBI GenBank database (accession no: HQ331525).
\end{abstract}

Keywords: Aeromonas hyrophila, Outer Membrane Protein, Carassius auratus, Cloning

\section{Introduction}

Globally the ornamental fish culture is a powerful income and employment generating industry. In the aquaculture sector, ornamental fish breeding, culture and trade provide excellent opportunities as a non-food fishery activity for employment and income generation. It is environment friendly, socially acceptable and involves low investment for adopting as a small scale enterprise with high return. The attractive coloration and quiet disposition of ornamental fish provide a source of joy and peace for people irrespective of age group ${ }^{1}$.

Goldfish are one of the most popular pets in the world. They are, undoubtedly, characterized by brilliant metallic gold and reddish coloration. The Goldfish, C. auratus contain the golden colour pigment due to the presence of erythrophore. It is highly adaptable species gaining important commercial value in the export trade. This fish has high susceptibility to aeromonads and are commonly valuable for experimental animals ${ }^{2}$.

In Asian countries fish culture continues to be destroyed by bacterial diseases such as Motile Aeromonads Septicaemia (MAS), furunculosis and edwardsiellosis. Among these, MAS caused by $A$. hydrophila is most widespread in freshwater fishes ${ }^{3}$. A. hydrophila is a ubiquitous, opportunistic free-living Gram negative bacterium prevalent in crowded aquatic habitats ${ }^{4}$. MAS infect a number of species producing stress related diseases with the common symptoms of ulcerations, exophthalmia and abdominal distension ${ }^{5,6}$. Recently, aquaculture is facing lots of problems due to aeromonads outbreaks. Potential virulence factors of $A$. hydrophila, which contribute to their pathogenicity, include the production of endotoxins, extra cellular enterotoxins, hemolysin, cytotoxins and protease, the ability to adhere the cells, and the possession of certain surface proteins ${ }^{7}$.

Outer membrane proteins (OMPs) from Aeromonas spp. have been identified as suitable targets for vaccine development in fish $^{8,9}$. Bacterial OMPs play a significant role in virulence as they comprise the outermost surface in contact with host cells and immune defense factors. Recombinant OMPs have been tested as possible vaccine antigens for $A$. hydrophila. Fang et al. ${ }^{10}$ showed significant protection against two isolates of $A$. hydrophila in blue gourami, Trichogaster richopterus immunized with a recombinant $43 \mathrm{kDa}$ OMP. More recently, a recombinant OMP (37 kDa) of $A$. hydrophila was produced and shown to be immunogenic in rohu carp ${ }^{11}$. The present study was undertaken to isolate virulent strain of $A$. hydrophila from the infected gold fish and clone the OMP gene of that strain.

*Corresponding author:

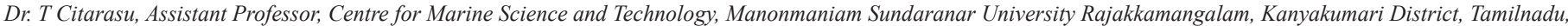
India 629502.Telefax: +91-4652-253078; E-mail: citarasu@gmail.com 
Viji et al.

\section{Materials and Methods}

\section{Isolation of A. hydrophila}

Infected goldfish were collected from J.J. fish farm, Nagercoil, Tamil Nadu, India and aseptically bagged in sterile polythene bags and transported to Lab. Infected fish samples such as muscle tissue, intestine, body fluid and gills were dissected out and homogenized in $10 \mathrm{ml}$ sterile alkaline peptone water. Homogenates were serially diluted up to $10^{-6}$ in sterile normal saline solution and 100il aliquots of each dilution were plated on Aeromonas isolation media using spread plate technique in duplicate. The plates were incubated at $37^{\circ} \mathrm{C}$ for $16-18 \mathrm{hr}$. Typical green colonies of $2-5 \mathrm{~mm}$ in diameter were subjected to biochemical tests for identification of $A$. hydrophila. The cultures were stored at $-80^{\circ} \mathrm{C}$ in $15 \%(\mathrm{v} / \mathrm{v})$ glycerol for further studies.

\section{Identification of A. hydrophila}

A. hydrophila were identified biochemically to species level by using 14 chosen tests and such as motility, Kovac's oxidase, oxidation and fermentation, catalase, indole, methyl red, urease, haemolysin production, sugar fermentation, Voges-Prokauer, nitrate reduction, $\mathrm{H}_{2} \mathrm{~S}$ production, lysine decarboxylase and arginine dihydrolase.

\section{Virulent studies}

$L D_{50}$

C. auratus having the body weight ranged between 30 to $40 \mathrm{~g}$ were used for $\mathrm{LD}_{50}$ studies. A. hydrophila of a concentration ranged between $10^{5}$ to $10^{9} \mathrm{cfu} / \mathrm{ml}$ in PBS ( $\mathrm{pH} 7.2$ ) injected intraperitoneally to $0.1 \mathrm{ml} /$ fish using 3 test group for each concentration and the control test group were injected intra peritoneally with $0.1 \mathrm{ml}$ of PBS ( $\mathrm{pH} 7.2$ ). Fish groups were observed for a period of 7 days and the lethal dose $\left(\mathrm{LD}_{50}\right)$ was determined.

\section{Proteolytic and Haemolytic activity}

Proteolytic activity of $A$. hydrophila was determined by production of a clear zone of proteolysis around the colonies on skim milk agar plates incubated at $37^{\circ} \mathrm{C}$ for $24 \mathrm{hr}$. Haemolytic activity was determined by producing a zone of haemolysis around the colonies on blood agar plates containing $2 \%(\mathrm{v} / \mathrm{v})$ human blood.

\section{Challange test}

In order to study the virulence of the isolated strains, fresh culture of different $A$. hydrophila isolates were diluted into $0.5 \% \mathrm{NaCl}$ and injected intraperitoneally to C. auratus in a dose of $3 \times 10^{7} \mathrm{cfu} /$ $\mathrm{ml}$. Each group had 10 fishes in triplicate and a control group is also maintained. The control group was injected with $100 \mu$ sterile $0.5 \% \mathrm{NaCl}$ without bacteria. The fish were observed up to 7 days and any dead specimens were removed for routine bacteriological examination.

\section{Cloning of OMP gene}

Genomic DNA was extracted from $24 \mathrm{hr}$ old cultures of $A$. hydrophila which was grown in Tryptone soya broth. In short,
$1 \mathrm{ml}$ of culture was taken in an eppndorf tube, spun at 3000rpm and extracted the DNA using miniprep DNA easy kit (Qiagen, Hamburg, Germany) as per the manufacturer's protocol. DNA was quantified by Nanodrop 1000 (Thermoscientific) and samples were stored at $-20^{\circ} \mathrm{C}$ until further use.

\section{Primer designing and PCR amplification}

The OMP-gene primer was designed and synthesized (SigmaAldrich, Bangalore) following the NCBI database sequence. The sequence details of the primers are OMP-TS F 5, CCCAAGCTTATGGCAGTGGTTTATGACAAA 3'; OMP TS R 5'AACTGCAGTTAGAAGTTGTATTGCAGGGC 3'. The OMPTS gene was amplified from the genomic DNA of $A$. hydrophila. The PCR protocol was, denaturation of DNA at $94^{\circ} \mathrm{C}$ for $5 \mathrm{mins}$ followed by 33 cycles consisting of $94^{\circ} \mathrm{C}$ for $30,50^{\circ} \mathrm{C}$ for $1 \mathrm{~min}$ and $72^{\circ} \mathrm{C}$ for $1.5 \mathrm{~min}$. After completion of 33 cycles, an extended time of $10 \mathrm{~min}$ at $72^{\circ} \mathrm{C}$ was maintained. The amplified PCR product had $1008 \mathrm{bp}$, resolved on a $1 \%(\mathrm{w} / \mathrm{v})$ low melting point agarose gel in 1 X TAE buffer, with a $1 \mathrm{~kb}$ ladder (fermentas) and visualized with ethidium bromide staining in Gel documentation.

\section{Restriction and digestion}

The PCR products were excised from the agarose gels using sterile blade and purified using gel extraction kit (Qiagen). The purified PCR products of OMP TS were double digested with the restriction enzymes Nde I and Xho I. The digested PCR products were run on an agarose gel, excised and purified using gel extraction kit again.

\section{Ligation and transformation}

The purified OMP TS products were ligated to T Easy Vector, $\mathrm{pTZ57R/T}$. The ligation reaction was performed by preparing a 5 il of ligation mix containing $0.5 \mu \mathrm{l}$ of vector and $3.5 \mu \mathrm{l}$ of purified PCR product. The insert and vector concentration maintained at the ratio of 3:1 respectively and incubated the mix overnight at $4^{\circ}$ C. Five micro liter of ligated plasmid was transformed to $E$. coli $\mathrm{DH}_{5} \alpha$ super competent cells and the positive clones were amplified using the OMP TS Primers.

\section{Plasmid isolation, Sequencing and submission}

Recombinant Plasmid (OMP TS-pTZ57R/T) was isolated from the positive $\mathrm{DH}_{5} \alpha$ transformants using mini prep plasmid isolation kit (Qiagen, Hamburg, Germany) as per the manufacturer's instructions. The recombinant plasmids were sequenced by the primers, M13+ and M13- (Macrogen 3730XL7, South Korea). The Nucleotide sequence of OMP gene was submitted to NCBI GenBank database (accession no: HQ331525).

\section{Results and Discussion}

The isolated bacteria from body fluid, intestine, gills, and muscle of infected goldfish were confirmed as $A$. hydrophila. The isolates from body fluid (AHV1), intestine (AHV2) of highly infected fish and muscle of low infected (AH3) fish were found to be motile, Gram negative, citrate, oxidase and catalase positive. The AHV1 and AHV2 showed strong proteolytic and haemolytic activities 
(Table 1) A. hydrophila has received particular attention because of its association with soft tissue, wound, and blood infections ${ }^{12}$. Boulanger et al. ${ }^{13}$ reported that $A$. hydrophila could be isolated from cutaneous lesions and kidneys of diseased fish, whereas both $A$. hydrophila and A. sobria could be recovered from the intestine of normal fish. Motile aeromonads that have been taken from lesions on diseased fish have been shown to have a greater chemotactic response to skin mucus than isolates that were obtained as free-living organisms from pond water ${ }^{14}$. Nordmann and Poirel ${ }^{15}$ reported that Aeromonas spp. are Gram-negative, rod shaped, mainly motile, facultative anaerobic, oxidase positive and glucose fermenting bacteria. They have recently been transferred from Vibrionaceae to their own family Aeromonadaceae ${ }^{16}$.

The relationship between the distribution of three $A$. hydrophila strains and their pathogenicities against $C$. auratus are shown in the Table 2. The $\mathrm{LD}_{50}$ data revealed that, the fish $C$. auratus highly susceptible to AHV1 and AHV2. The AH3 and MTCC strains had less virulence of 45 and $25 \%$ lethal rate respectively due to their low level of extra cellular products expression. $\mathrm{Kou}^{17}$ found that many of the virulent, avirulent, and attenuated aeromonads that he studied possessed hemorrhagic factors and lethal toxins. The virulent bacteria had quantitatively more toxic potential than did their avirulent or attenuated counterparts. $A$. hydrophila causes infections in food and ornamental fishes, there by posing a threat to the development of the aquaculture enterprise. Several strains of $A$. hydrophila release extracellular toxins for its pathogenicity ${ }^{18,19}$. Chopra et al. ${ }^{20}$ reported that, the haemolysins released by Aeromonas are cytotoxic and cause lysis of erythrocyte and play important roles in pathogenesis. The role of protease enzyme is to provide nutrients by breaking down host proteins into small molecules capable of entering the bacterial cell ${ }^{21,22}$. De Figuerirredo and Plumb ${ }^{23}$ have found that environmental and clinical isolates differed in virulence when injected into channel catfish. $\mathrm{LD}_{50}$ values from diseased fish were $6.4 \times 10^{4} \mathrm{cfu}$, compared with $1.5 \times 10^{6} \mathrm{cfu}$ for environmental isolates. In general, virulent isolates of $A$. hydrophila has an $\mathrm{LD}_{50}$ values of $10^{4}$ to $10^{5} \mathrm{cfu}$, while strains which do not kill fish at $10^{7}$ cfu are considered non-virulent ${ }^{24}$. The higher lethal rate in C. auratus due to the AHV1 and AHV2 was also reflected in the proteolytic and haemolytic activities. These activities were higher in AHV1 followed by AHV2, AH3 and MTCC strains. This may due to the higher amount of extra cellular products secretions (Table 3).

Table 1. Morphological and biochemical confirmation of A. hydrophila (AHV1, AHV2 and AH3) isolated from infected Gold fish

\begin{tabular}{|c|c|c|c|c|c|}
\hline \multicolumn{3}{|c|}{ S.No } & \multirow{2}{*}{$\begin{array}{c}\text { Confirmative Test } \\
\text { AHV1 } \\
\text { motile }\end{array}$} & \multirow{2}{*}{$\begin{array}{c}\text { A. hydrophila isolates } \\
\text { AHV2 } \\
\text { motile }\end{array}$} & \multirow{2}{*}{$\frac{\mathrm{AH} 3}{\text { motile }}$} \\
\hline 1 & Motility & & & & \\
\hline 3 & Cell shape & & rod & rod & rod \\
\hline 4 & Indole & & + & + & + \\
\hline 6 & Voges proskauer & & + & + & + \\
\hline 7 & Citrate & & + & + & + \\
\hline 8 & Oxidase & & + & + & + \\
\hline 9 & Catalase & & + & + & + \\
\hline 13 & Hemolysin & & ++ & ++ & + \\
\hline 14 & Starch hydrolysis & & + & + & + \\
\hline 15 & Urea & - & - & - & \\
\hline \multirow[t]{5}{*}{16} & Carbohydr-ate fermentati-on & D-Glucose & + & + & + \\
\hline & & Sucrose & + & + & + \\
\hline & & Lactose & + & + & + \\
\hline & & Maltose & + & + & + \\
\hline & & Galactose & + & + & + \\
\hline
\end{tabular}

AHV: A. hydrophila Virulent; AH: A. hydrophila 
Table 2. Relationship between the distribution of three virulent A. hydrophila strains and their pathogenicities to Carassius auratus

\begin{tabular}{lcccc}
\hline S.No & Test groups & Strains & Lethal rate (\%) & Virulence \\
\hline 1 & Fish group 1 & Control & 0 & - \\
2 & Fish group 2 & AHV1 & 100 & Strong \\
3 & Fish group 3 & AHV2 & 100 & Strong \\
4 & Fish group 4 & AH3 & 45 & Medium \\
5 & Fish Group 5 & MTCC & 25 & Low \\
\hline
\end{tabular}

Table 3. Proteolytic and Haemolytic activity of virulent A. hydrophila isolated from infected gold fish in comparison with MTCC strain

\begin{tabular}{lccc}
\hline S. No & Strains & Proteolytic activity & Haemolytic activity \\
\hline 1 & AHV1 & ++++ & ++++ \\
2 & AHV2 & +++ & ++++ \\
3 & AH3 & ++ & ++ \\
4 & MTCC & + & + \\
\hline
\end{tabular}

The survival of gold fish $C$. auratus against $A$. hydrophila challenge was given in the Fig 1 . The fish group survived $95 \%$ after $5^{\text {th }}$ day of post challenge in the blank control had no $A$. hydrophila challenge. The survival was significantly $(\mathrm{P}<0.05)$ decreased to $70 \%$ after $5^{\text {th }}$ day of post challenge in the MTTC challenged groups. The groups that, succumbed to death $100 \%$ mortality ( $0 \%$ survival) in the AHV1 and AHV2 challenged fishes after $4^{\text {th }}$ day of post challenge. The AH3 challenged group had only $40 \%$ survival due to less virulence. The preparation of ECP of different $A$. hydrophila strains were injected to the fingerlings of hybrid catfish ${ }^{25}$. The ECP of highly virulent strain resulted in $100 \%$ mortality within 18 hours while the low virulent strains showed $100 \%$ mortality within 96 hours.

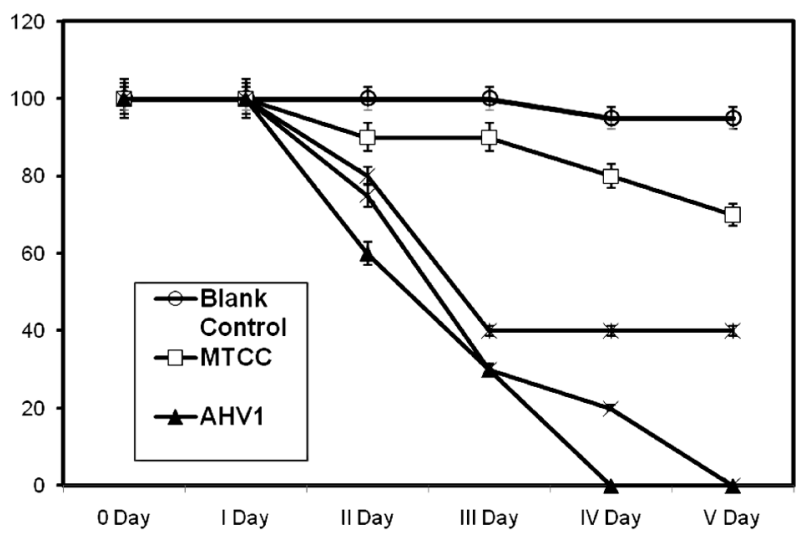

Figure 1. Percentage survival of C. auratus after injecting A. hydrophila at different intervals

The OMP gene was successfully amplified from the genomic DNA of virulent $A$. hydrophila AHV1 strain, having a size of 1008 base pairs (Fig 2). Further, the amplified gene was successfully cloned to pTZ57R/T - vector (Fig 3) and sequenced (Fig 4). The sequence was submitted to NCBI database (Accession number HQ331525) and this sequence resemble to various $A$. hydrophila isolates. In gram negative pathogenic

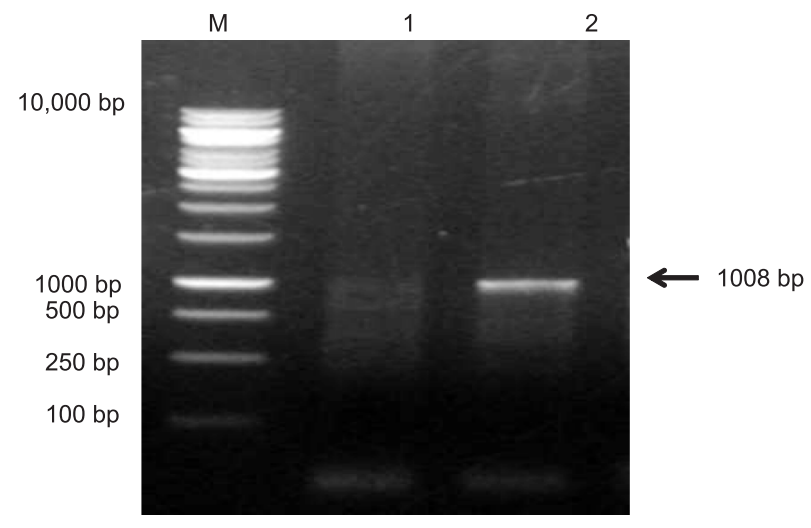

Figure 2. $P C R$ amplification of $O M P$ gene from Genomic DNA of virulent A. hydrophila AHV1, Lanes 1: Marker; 2. Negative control and 3: AHV1

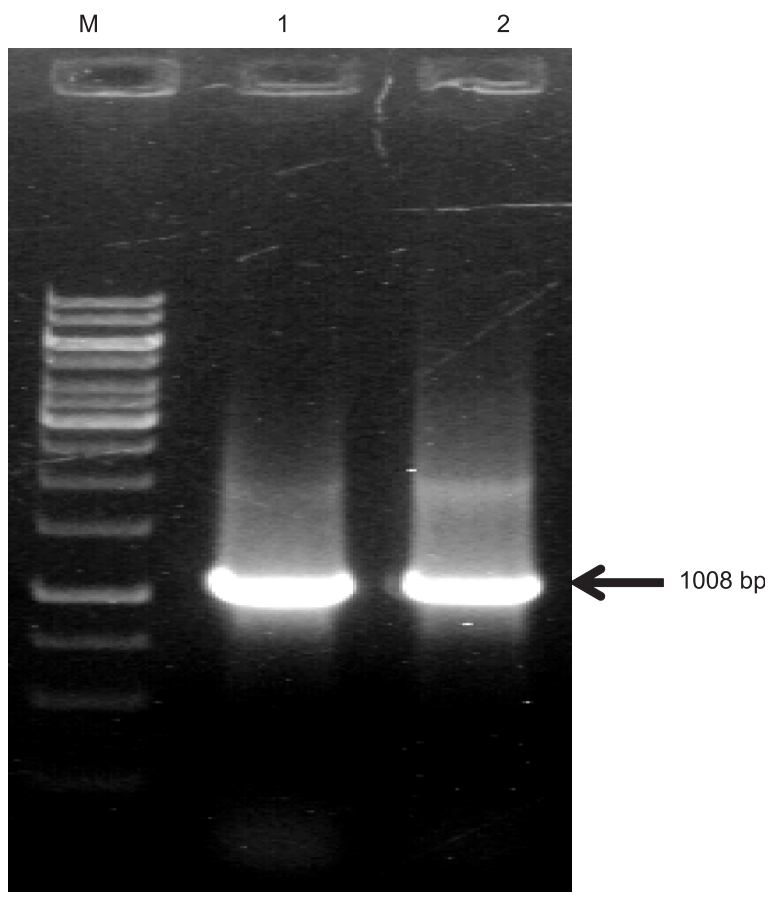

Figure 3. $P C R$ amplification of $O M P$ gene from recombinant plasmid (OMP-pTZ57R/T) Lanes 1: Marker; 2\&3: OMP-AHV1 positive clones 
Virulence Factors and Molecular cloning of Outer Membrane Protein (OMP)

1 CHHAHRG TCCGGTCTC TCTAT TGAHTTGCTTTGATGTT 40

41 GGCCCAACH CCCCTTCCT TTTATATCGCAACAGCT CTATA 80

81 CCCCCAGATTGAATGCCAGCGgTTCGgCATCGCCTCGAC 120

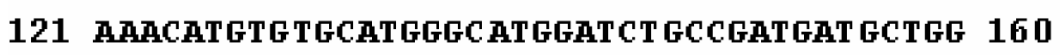

161 ACAACGCTT TCGGTCCTC CACTGCTGCAGAAGAGC GACCC 200

201 GTGCCCGgAGACGGAGAAAACCGCTTTTGGCTTTGTCATT 240

241 CTGGCGCTGCCGGTGTTC CTGATGGAGCGTATCAT CGGTG 280

281 ACGTCTGgGgTATGTGCCTGTGgGCAATgCTCGgGgTAGC 320

321 GTTCTTTACCTGGGCGTT TATCGTCAGCCTGGGGGCGAAA 360

361 AAAGCGTGGATGCGTCTGGTATCCTCCTGCTGCTGGCTGC 400

401 CGCGCTGGTAAGCGTGCGTCCTCTTCAGGACTGGGCGTTC 440

441 gGCTCGCCGgTCGgCCAGACGCAGgCGCATTTGAACTTCA 480

481 T CCAGAT TAAGATCGTTGATGAGCTCAACAGCGCGCTCTT 520

521 ACAGGCAAAAGGCAAACC GGTGATGCTCGATCTCTATGCC 560

561 GACTGGTGCGTCGCCTGCAAAGAGTT TGAAAAATACACCT 600

601 T TTAGCGAT CCACANHCA CAAAATGC CCTGAAAGAGACTG 640

641 T TCTGCTCCAGGCAAACG TGACACCCAACAAGCACACGAT 680

681 ACGCTCTGC TGAAGCAGC T TAACGTC CTCAGACTGCAACC 720

721 ATTCTTTTT CTTCAAT CAACAGGGCCAGTAGCAGC CAGAA 760

761 AAGCGTGTAACCGTCGTT TATAGGAT GCTAGCGGCATTAG 800

801 CGCGCATTT GCGCAATCCGCCAGACG TAAACTACACTTTA 840

841 ACGgGACAAACCCGTGGG TATTAGCGAACGACATAACCGT 880

881 GCAAGCTGAAGACGTACT GT CACAAG CCCCTCCAATCACC 920

921 T CTCTACTGCAGTTTATC GGATCCGGGHCC

Figure 4. Sequence analysis of A. hydrophila OMP gene (HQ331525) from AHV1 after cloning

bacteria, the outer membrane proteins play an important role in infection and pathogenicity to the host ${ }^{26}$. The outer membrane proteins of the warm water fish pathogen, Aeromonas hydrophila have a role in the virulence of the organism and are potential candidates for vaccine development ${ }^{27}$. In the present study, the 1008 bp outer membrane protein, which had been shown to be an OMP TS in virulent AHV1 strain, was cloned. Fang et al. ${ }^{10}$ found significant protection against two isolates of A. hydrophila in blue gourami, Trichogaster trichopterus (75 and $87.5 \%$ RPS) immunized with a recombinant $43 \mathrm{kDa}$ OMP, while a recombinant $37 \mathrm{kDa}$ OMP of $A$. hydrophila has been shown to be immunogenic in rohu carp ${ }^{11}$. Ebanks et al. ${ }^{28}$ recorded 10 outer membrane proteins in the same region which included homologues of OMPC, OMPAI/AII, OMPK, OMPTolC, OMPD and other OMPs involved in nutrient acquisition in $A$. salmonicida by proteomics. The major drawbacks in ornamental goldfish industry are lack of availability of precise disease diagnostic tools and vaccines against deadly haemorrhagic ulceration. The present work we conclude that the PCR amplification of OMP gene as a diagnostic tool in infected/ non-infected ornamental fishes. Also the OMP clone will be used for developing vaccines against ornamental/ fresh water fish species against A. hydrophila infection.

Acknowledgements

One of the authors V. Thanga Viji gratefully acknowledged the UGC-Networking Resource Centre in Biological Sciences (NRCBS), School of Biological Sciences, Madurai Kamaraj University, India for its financial support, in the form of NRCBS visiting fellowship during August to September 2009. 


\section{References}

1. Swain S K, Mallik D, Mishra S, Sarkar B and Routray P. 2007. Ornamental fish as model animals for biotechnological research. In: Environmental Biotechnology (Ed. Mishra and Juwarkar) pp. 293328. APH publ.corp., Delhi.

2. Austin B and Austin D A .1993. Bacterial fish pathogens. In: Schuster Chichester S, (Eds) Diseases of farmed and wild ûsh. $2^{\text {nd }}$ ed., p.111-7, Springer Publication.

3. Karunasagar I, Rosalind G and Karunasagar J .1991. Immunological response of the Indian major carps to Aeromonas hydrophila vaccine. J Fish Dis. 14: 413-7.

4. Hazen TC, Fliermans CB, Hirsch Pand Esch GW. 1978. Prevalence and distribution of Aeromonas hydrophila in the USA. J Appl Environ Microbiol. 36: 731-8.

5. Miyazaki S .1985. A histopathological study of motile aeromonad disease in Ayu Plecoglossus altivelis. Fish Pathol. 20: 55-60.

6. Harikrishnan R, Nisha Rani M and Balasundaram C. 2003. Hematological and biochemical parameters in common carp, Cyprinus carpio, following herbal treatment for Aeromonas hydrophila infection. Aquaculture. 221: 41-50.

7. Howard S P and Buckley J T. 1985. Activation of the hole forming toxin aerolysin by extracellular processing. J Bacteriol. 163: $336-$ 340 .

8. Fang H M, Ling K C, Ge R and Sin M. 2000. Enhancement of protective immunity in blue gourami, Trichogaster trichopterus (Pallas), against Aeromonas hydrophila and Vibrio anguillarum by A. hydrophila major adhesion. J Fish Dis. 23: 137"145.

9. Bricknell I R, King J A, Bowden T J and Ellis A E .1999. Duration of protective antibodies, and the correlation with protection in Atlantic salmon (Salmo salar L.) following vaccination with an Aeromonas salmonicida vaccine containing iron-regulated outer membrane proteins and secretary polysaccharide. Fish Shellfish Immunol. 9: 139-51.

10. Fang H M, Ge R and Sin Y M .2004.Cloning, characterization and expression of Aeromonas hydrophila major adhesin. Fish Shellfish Immunol. 16: 645-58.

11. Khushiramani R, Girisha S K, Karunasagar I and Karunasagar I . 2007. Cloning and expression of an outer membrane protein omp TS of Aeromonas hydrophila and study of immunogenicity in fish. Protein Expr Purif. 51: 303-7.

12. Phillips J A, Bernhardt H E and Rosenthal S G. 1974. Aeromonas hydrophila infections. Pediatrics. 53: 110.

13. Boulanger Y, Lallier R and Cousineau G. 1977. Isolation of enterotoxigenic Aeromonas from fish. Can J Microbiol. 23:11611164.

14. Cipriano R C, Bullock G L and Pyle S W . 1984. Aeromonas Hydrophila and motile Aeromonad Septicemias of Fish. 68, United States department of the interior Fish and Wildlife Service Division of Fishery Research Washington, D. C. 20240
15. Nordmann P and Poirel L. 2002. Emerging carbapenemases in Gram-negative aerobes. Clinical Microbiol Infect. 8: 321- 331.

16. Ormen O, Pereinar G, Lassen J and Figueras M J. 2005. Lack of agreement between biochemical and genetic identification Aeromonas spp. Acta Patolugia Microbiologicet Immunologica Scandinavica. 113: $203-210$.

17. Kou GH. 1973. Studies on the fish pathogen Aeromonas liquefaaiens. II. The connections between pathogenic properties and the activities of toxic substances. J Fish Soc Taiw. 2: 42 - 46.

18. Esteve C and Birbeck T H. 2004. Secretion of haemolysins and proteases by Aeromonas hydrophila E063: separation and characterization of the serine protease (caseinase) and the metalloprotease (elastase). J Appl Microbiol. 96: 994-1001.

19. Galindo C L, Fadl A A, Sha J, Gutierrez Jr C, Boldogh VL, Agarwal B B and Chopra A K. 2004. Aeromonas hydrophila cytotoxic enterotoxin activates mitogen-activated protein kinases and induces apoptosis in murine macrophages and human intestinal epithelial cells. J Biol Chem. 279: 37597-37612.

20. Chopra A K, Xu X J, Ribardo D, Gonzalez M, Kuhl K, Peterson J W and Houston CW. 2000. The cytotoxic enterotoxic of Aeromonas hydrophila induces proinflammatory cytokine production and activates arachidonic anid metabolism in macrophages. Infect Immun. 68: $2808-2818$.

21. Cicmanec JF and Holder IA. 1979. Growth of Pseudomonas aeruginosa in normal and burned skin extract: role of extracellular proteases. Infect Immun. 25: 477-483

22. Sakai D K. 1985. Efficacy of specific antibody against agglutinating Aeromonas salmonicida strains infectivity and vaccination with inactivated protease. J Fish Dis. 8: 397 -405.

23. De Figueirredo J and Plumb J A. 1977. Virulence of different isolates of Aeromonas hydrophila in channel catfish. Aquaculture. 11: 349 354 .

24. Stevenson R M. 1988. Vaccination against Aeromonas hydrophila. In: Ellis, A.E. (Ed.), Fish vaccination. Harcourt Brace Jovanovich. $112-123$

25. Sirirat $\mathrm{T}$, Intuseth $\mathrm{J}$, Chanphong $\mathrm{J}$, Thomson $\mathrm{K}$, Chinabut $\mathrm{S}$ and Adams A .1999. Characterization of Aeromonas hydrophila extracellular products with reference to toxicity, virulence, protein profiles and antigeneicity, Asi Fish Sci. 12: 371-379.

26. Tsolis R M. 2002. Comparative genome analysis of the aproteobacteria: Relationships between plant and animal pathogens and host specificity. Proc Natl Acad Sci USA. 99: 12503-12505.

27. Merino S, Rubires X, Aguilar A and Tomas J M. 1996. The O: 34antigen lipopolysaccharide as an adhesin in Aeromonas hydrophila. FEMS Microbiol Lett 139: 97-101.

28. Ebanks R O, Goguen M, McKinnon S, Pinto DM and Ross N W. 2005. Identification of the major outer membrane proteins of Aeromonas salmonicida. Dis Aquat Organ. 68: 29-38. 